\title{
A FORMAÇÃo INICIAL E INICIAÇÃO À DOCÊNCIA EM QUÍMICA NA UFMT: HISTÓRIAS E EXPERIÊNCIAS
}

\author{
THE INITIAL FORMATION AND INITIATION TO TEACHING IN CHEMISTRY AT \\ UFMT: STORIES AND EXPERIENCES
}

DOI: http://dx.doi.org/10.23926/RPD.2526-2149.2019.v4.n1.p275-301.id435

\author{
Marcel Thiago \\ Damasceno Ribeiro \\ Doutor em Educação em \\ Ciências e Matemática \\ (REAMEC/UFMT) \\ Professor na Universidade \\ Federal de Mato Grosso \\ (UFMT) \\ marcel@ufmt.br
}

\begin{abstract}
Resumo: Este artigo resulta de uma pesquisa teórica sobre a formação inicial e iniciação à docência em Química na UFMT, por meio de uma análise documental, e que compôs parte do texto da pesquisa de doutorado intitulada Saberes Científicos e Pedagógicos de Conteúdo expressos por Professores Egressos do Programa de Bolsa de Iniciação à Docência em Química da UFMT, desenvolvida pela Rede Amazônica de Educação em Ciências e Matemática (REAMEC). E tem por objetivo narrar os aspectos evolutivos do curso de Licenciatura em Química do campus Cuiabá-UFMT, em diálogo com a literatura pertinente, desde sua criação até o contexto de formação do Programa Institucional de Bolsa de Iniciação à Docência (PIBID) na UFMT e o Subprojeto Química. A análise dos documentos (PPC do curso, artigos, capítulo de livros, entre outros), que compuseram o corpus da pesquisa evidencia a experiência do curso de Licenciatura em Química e o desenvolvimento do PIBID, como um lócus privilegiado para a formação de educadores químicos no Estado de Mato Grosso.
\end{abstract}

Palavras-chave: Relato de Experiência; Formação Inicial em Química; Iniciação à Docência em Química; Educação Química.

\begin{abstract}
This article results from a theoretical research on the initial formation and initiation to teaching in Chemistry at the UFMT, through a documentary analysis, and that composed part of the text of the doctoral research titled Scientific and Pedagogical Knowledge of Content expressed by Teachers Graduates of the Chemistry Education Initiation Scholarship of UFMT, developed by the Amazonian Network for Education in Science and Mathematics (REAMEC). The purpose of this course is to describe the evolutionary aspects of the undergraduate course in Chemistry at the Cuiabá-UFMT campus, in dialogue with the pertinent literature, from its creation to the training context of the Institutional Program for Initiation to Teaching (PIBID) at UFMT and the Chemical Subproject. The analysis of the documents (course PPC, articles, book chapter, among others), that compose the corpus of the research is evidenced the experience of the course of Degree in Chemistry and the development of PIBID as a privileged locus for the chemical educators in the State of Mato Grosso.

Keywords: Experience Report; Initial Formation in Chemistry; Introduction to Teaching in Chemistry; Chemical Education.
\end{abstract}




\section{CONSIDERAÇÕES INICIAIS}

Este artigo se trata de um relato de experiência sobre a formação inicial e iniciação à docência em Química na Universidade Federal de Mato Grosso (UFMT), por meio de uma análise documental, e que compôs parte do texto da pesquisa de doutorado intitulada: Saberes Científicos e Pedagógicos de Conteúdo expressos por Professores Egressos do Programa de Bolsa de Iniciação à Docência em Química da UFMT ${ }^{l}$. Neste sentido, apresenta-se a eclosão de um novo ramo da Química, a Educação Química, em termos nacionais e locais. Para tanto, consulta-se a legislação vigente, em termos brasileiros e institucionais, considerando aspectos evolutivos do curso de Licenciatura em Química da UFMT, em diálogo com a literatura pertinente, desde sua criação até o contexto de formação do Programa Institucional de Bolsa de Iniciação à Docência na UFMT e o seu Subprojeto Química.

Um dos caminhos escolhidos para a formação inicial de pesquisador e educador químico, foi a opção consciente pela área de Educação Química. Consoante com isso se faz um breve histórico da constituição da área de Educação Química no Brasil, considerando esse aspecto pertinente neste relato de experiência, pois nesta área, mais que em outras áreas da Química, é preciso lutar pelo reconhecimento externo (principalmente dos agentes financiadores de pesquisas) e interno (junto à comunidade epistêmica dos químicos), como afirma Chassot (2014, p. 55): “em nosso meio pode-se afirmar que o reconhecimento dos que nos são próximos tem sido mais árduo de conquistar que dos externos". A afirmação desse educador químico foi feita pela dura experiência pessoal pela qual passou em ver diferentes oportunidades e iniciativas nessa área sendo bloqueadas. Essa triste experiência faz parte da vida do pesquisador e de muitos educadores químicos no Brasil ao terem sempre que lutar dentro da própria comunidade por reconhecimento.

Um maior reconhecimento da área de Educação Química, nas palavras de Schnetzler e Aragão (1995), depende fundamentalmente da divulgação da capacidade de resolver problemas, que não podem ser resolvidos pelas outras áreas da Química, já que o domínio do conhecimento químico é uma condição necessária, mas não suficiente para se alcançar um bom processo de ensino e aprendizagem nessa ciência.

Pertencer à área de Educação Química é diferente de se situar em outras áreas da Química, que se preocupam com interações de átomos e de moléculas, com a dinâmica e mecanismos de transformações químicas, o que, sem dúvida, é relevante. Contudo, como

\footnotetext{
${ }^{1}$ Lança-se mão do uso da fonte do texto em negrito ou itálico, quando se tem intenção de chamar a atenção do leitor para algum termo ou expressão.
} 
integrante da área em Educação Química, além de todas essas preocupações, inerentes ao ramo da Química, há o envolvimento com interações entre pessoas (estudantes e professores) e dessas com o conhecimento na dinâmica de construir uma educação de qualidade e de educar para a cidadania, por meio do ensino e da aprendizagem da Química.

A identidade da área de Educação Química como campo de investigação é marcada pela especificidade do conhecimento científico, que está na raiz dos problemas de ensino e aprendizagem investigados. Schnetzler (2002) argumenta que:

\begin{abstract}
Esse campo de investigação não tem o propósito de se buscar métodos didáticos mais adequados ao ensino daquele conhecimento, mas sim, de investigar processos que melhor deem conta de reelaborações conceituais ou transposições didáticas necessárias ao seu ensino em contextos escolares determinados. Isso significa que o ensino de ciências/química implica a transformação do conhecimento científico/químico em conhecimento escolar, configurando a necessidade de criação de um novo campo de estudo e investigação, no qual questões centrais sobre o que, como e porque ensinar ciências/química configura o cerne das pesquisas (p. 15).
\end{abstract}

Diante desse contexto, constata-se que a área de Educação Química no Brasil, em termos de pesquisas é muito jovem, tendo mais de cinquenta anos em termos internacionais e cerca de quarenta e um anos em termos brasileiros, já que as primeiras pesquisas em ensino de Química no Brasil datam de 1978. Devido ao pouco tempo como área de investigação, é natural que a Educação Química, tanto em termos internacionais como nacionais, não mereça ainda, por parte da comunidade Química, como um todo, a mesma credibilidade dos outros ramos da Química, como química orgânica, físico-química, analítica, entre outros.

De acordo com Schnetzler (2002), os pesquisadores precursores da área de Educação Química se sentem orgulhosos de terem dado os primeiros passos nesse novo campo de pesquisa no Brasil. A autora revela que sem Áttico Chassot, Letícia Parente, Luiz Otávio Amaral, Luiz Roberto Pitombo, Mansur Lufti, Maria Eunice Ribeiro Marcondes, Otávio Maldaner, Roberto Ribeiro da Silva, Romeu Rocha-Filho, Roque Moraes, a própria Roseli Pacheco Schnetzler, entre outros, certamente a área de Educação Química no país não teria ido tão longe como foi, formando e lançando novas gerações para a meta de constituir a área de pesquisa em ensino de Química no Brasil. Segundo essa autora, o que unia esses pesquisadores e educadores pioneiros era a necessidade, a condição e a sensação de ostracismo, que julgavam injustas e a crença na educação em Química para um país melhor.

Nesse sentido, Schnetzler (2010) revela que no espaço de apenas quatro décadas houve a constituição de uma comunidade de educadores químicos brasileiros, que vêm desenvolvendo pesquisas em uma nova área da Química, a Educação Química. E essas pesquisas trazem os seguintes temas: identificação de concepções alternativas dos alunos e propostas de modelos de 
ensino, que levem em conta, resolução de problemas, experimentação e práticas de laboratório, análise de materiais didáticos, relações entre ciência, tecnologia, sociedade e ambiente em processos de ensino e aprendizagem, linguagem e comunicação, a problemática e o emprego de modelos e analogias, concepções epistemológicas de professores, proposta para uma formação docente mais adequada, questões curriculares e de avaliação, e o papel das novas tecnologias de comunicação.

Um dado de grande relevância, que evidencia o crescente desenvolvimento da Educação Química, no país, diz respeito às realizações sistemáticas de vários Encontros Nacionais e Regionais sobre o ensino de Química. Schnetzler e Aragão (1995) relatam o histórico da realização desses encontros, como a realização anual dos EDEQ (Encontro de Debates sobre Ensino de Química), desde 1980, e dos ECODEQC (Encontro Centro-Oeste de Debates sobre Ensino de Química e Ciências), a partir de 1989; dos ENNEQ (Encontro Norte-Nordeste de Ensino de Química) a partir de 1990, e dos ESEQS (Encontro Sudeste de Ensino de Química) desde 1992, que ocorrem à semelhança dos ENEQ (Encontro Nacional de Ensino de Química), bianualmente, sendo que esse último começou a fazer história em 1982.

Com o desenvolvimento da área de Educação Química no Brasil, é de se esperar que as pesquisas tenham gerado avanços significativos no conhecimento e que possam contribuir, de forma potencial, para a melhoria do trabalho docente em Química no país (SCHNETZLER e ARAGÃO, 1995).

De acordo com Chassot (1993), Educação Química é uma área de fronteira entre a Educação e a Química, que se preocupa prioritariamente com o significado do ensino de Química, nos currículos dos diferentes graus de ensino. O educador químico é o profissional que possui formação acadêmica em Química e que usa essa ciência para fazer Educação. O autor ainda exemplifica que o professor de Química, mesmo que não vinculado a um grupo de pesquisa, mas que utiliza a sala de aula e faz dessa um laboratório para aprimorar a ação docente, é educador químico.

Nessa perspectiva, Maldaner (2008) complementa que, em uma visão ampliada, educadores químicos são sujeitos sociais ou pessoas que lidam e trabalham com as coisas da Química e sua atenção se volta mais a aspectos como:

Processos de ensino e aprendizagem em Química; compreensão da Química como ciência; responsabilidade social no uso dos conhecimentos da Química; currículos de formação em Química; evolução/revolução química na história humana; Química e qualidade de vida; ética na pesquisa química; conhecimentos profissionais dos professores de Química (p. 271). 
O objetivo central de trabalhar com os conhecimentos químicos e fazer Educação com esses conhecimentos, segundo pesquisa realizada por Santos (1992) envolvendo vários educadores químicos brasileiros, é de contribuir para a formação do cidadão, o que implica a necessidade de vincular o conteúdo químico com o contexto social, no qual o estudante está inserido. Essa concepção de ensino de Química, de acordo com Schnetzler (2008), traz ecos de um movimento iniciado em educação em Ciências, em âmbito internacional, desde o final da década de 1970, que defende a inclusão do ensino de CTSA - Ciência, Tecnologia Sociedade e Ambiente nos cursos de Ciências.

A Licenciatura em Química é o locus privilegiado para a formação de educadores químicos no Brasil. Adiante, apresenta-se o relato de experiência do curso de Licenciatura em Química na UFMT do campus Cuiabá, por meio de um breve histórico da criação até a implantação da estrutura curricular do curso, que ficou vigente de 1997/1 a 2009/2. Apresentase, também, a atual configuração do curso de Licenciatura em Química, com a nova estrutura curricular, que entrou em vigência em 2010/1, bem como o contexto do PIBID na UFMT.

\section{O CURSO de LiCENCIATURA EM QUímica da UFMT CAMPUS Cuiabá}

O primeiro curso de Química da UFMT foi criado no ano de 1972, com atribuição de bacharelado, juntamente com o Centro de Ciências Exatas e Tecnológicas (CCET), com a finalidade de proporcionar qualificação profissional com conhecimentos técnicos profundos aos alunos do curso de Química e de outros cursos, que demandassem conhecimentos químicos. O CCET, em sua criação, foi composto pelos Departamentos de Engenharia Civil, História Natural, Matemática, Física e Química, esse acoplando os dois ramos da ciência em um único Departamento (UFMT, 1997).

No ano de 1974, os cursos de Química, de Física, de Matemática e de História Natural foram transformados em cursos de Licenciatura em Ciências de curta duração, com habilitação em Química, em Física, em Matemática ou em História Natural. Após a conclusão da Licenciatura em Ciências de curta duração, o estudante, para obter a habilitação em Química de duração plena, devia cursar mais oitenta créditos equivalentes a 1200 horas, e de acordo com a estrutura curricular do curso de Ciências, com habilitação em Química, lhe era conferido o direito de exercer o magistério na Educação Básica (na época, o $1^{\circ}$ e $2^{\circ}$ graus).

Passados onze anos, no ano de 1985, o curso de Licenciatura em Ciências de curta duração, com suas respectivas habilitações específicas passou a ser Licenciatura Plena em Matemática, em Biologia, em Física e em Química. E foram instituídos os cursos de 
Licenciatura Plena em Química e o Bacharelado em Química. Porém, o estudante só poderia cursar o Bacharelado após a conclusão do curso de Licenciatura Plena em Química. Tal condição gerou questionamentos, à época, quanto à especificidade de cada profissional, atribuindo malfazeja fama de trampolim ao curso de licenciatura (UFMT, 1997).

No ano de 1990, a modalidade Bacharelado em Química passou a ficar desvinculada da Licenciatura plena e, após a conclusão das disciplinas do $1^{\circ}$ e $2^{\circ}$ semestres, o estudante deveria optar por uma das duas modalidades. Após essas mudanças, o curso de Licenciatura Plena em Química e o curso de Bacharelado em Química da UFMT foram reconhecidos pelo Ministério da Educação e do Desporto (MEC), por meio da Portaria n 1.521 , de 21 de outubro de 1993 (UFMT, 1997).

Finalmente, em 1997, os dois cursos foram totalmente separados e apresentados dessa forma no edital do vestibular da Universidade Federal de Mato Grosso, constituindo-se, a partir desse momento, em dois cursos distintos, ficando a escolha a critério do estudante, no momento de sua inscrição no processo seletivo de ingresso à UFMT.

No que concerne à matriz curricular do curso de Licenciatura em Química, a Resolução CONSEPE $n^{\circ} 65$, de 1985, estabelecia uma carga horária de 3.315 h/aula, que foi alterada pela Resolução CONSEPE n 24, de 1990, passando para a carga horária de 3.375 h/aula, o que foi alterado novamente para 3.405 h/aula, que deviam ser concluídas em um período máximo de seis anos, pela Resolução CONSEPE n 11 , de 05 de fevereiro de 2001.

As disciplinas foram agrupadas em cinco blocos para o curso de Licenciatura em Química, a saber:

Bloco I) Disciplinas de Formação Geral (Cálculo Diferencial e Integral I, II e II, Introdução à Ciência da Computação, Probabilidade e Estatística, Vetores e Geometria Analítica, Física Experimental I, II e III, Biologia, Filosofia da Ciência, Mineralogia, Legislação e Ética Profissional), Bloco II) Disciplinas de Formação Profissional ( Química Geral I e II, Química Orgânica I, II, III e IV, Química Inorgânica I, II e III, Química Analítica I, II, III e IV, Físico-Química I, II, III e IV, Bioquímica Geral, Química Bromatológica, Química do Ambiente), Bloco III) Disciplinas Pedagógicas (Psicologia da Educação V e VI, Didática III, Organização e Funcionamento da Educação Básica, Bioquímica Educacional e Práticas de Ensino de Química I, II e III), Bloco IV) Disciplinas Optativas (Bioquímica Avançada, Físico-Química IV, Inglês Técnico, Língua Portuguesa, Química Analítica V, Cálculo Numérico), e Bloco V) Disciplinas de Legislação Específica (Educação Física I e II). (UFMT, 1997, p. 26, grifo nosso). 
Pode-se perceber que essa estrutura curricular, vigente de 1997/1 a 2009/2, adotava o esquema 3+1 de formação ${ }^{2}$, ou seja, havia polarização entre Bacharelado e a Licenciatura. Sobre esse modelo de formação, Schnetzler (2008) tece severas críticas, pois de acordo com essa educadora e pesquisadora em Educação Química, a formação propiciada na maioria dos cursos de Licenciatura em Química do Brasil, por muitos anos, parecia estar pautada em uma visão simplista, qual seja, a de que ensinar é fácil, bastando saber o conteúdo químico e dominar algumas técnicas pedagógicas. Essa visão, de acordo com a pesquisadora:

É reforçada nas aulas de disciplinas de conteúdos químicos pela adoção do modelo de ensino-aprendizagem centrado na transmissão-recepção, pela ausência e despreocupação dos formadores (professores universitários) com reelaborações conceituais dos conteúdos que ministram para que estes pudessem se tornar disponíveis para serem ensinados pelos futuros professores nas escolas média e fundamental, livrando-os de serem adotados por livros didáticos de Química tradicionais (p. 25-26).

Para Schenetzler (2008), esse modelo de formação não integra as disciplinas de conteúdos químicos com as disciplinas pedagógicas, concebe e constrói a formação do professor como técnico, por ser pautada na racionalidade técnica ${ }^{3}$ e entende a atividade profissional como essencialmente instrumental, sendo essa dirigida para a solução de problemas, mediante a aplicação de teorias e de técnicas, conforme expresso por Schön (1992).

Pérez Gómez (1992) explicita que a racionalidade técnica é uma concepção epistemológica da prática, que foi herdada do positivismo, e que prevaleceu durante todo o século XX, servindo de referência para a educação e socialização dos profissionais, de um modo geral, e dos docentes em particular. $\mathrm{O}$ autor complementa que: "segundo a racionalidade técnica, a atividade profissional é, sobretudo, instrumental, dirigida para a solução de problemas mediante a aplicação rigorosa de teorias e técnicas científicas” (p.96).

De acordo com Schnetzler (2004), os únicos momentos da formação, que procuram fazer a ligação entre os conhecimentos do conteúdo específico e o conhecimento pedagógico para a realização do processo de ensino e aprendizagem, implicando transformações dos conhecimentos científicos apreendidos nas disciplinas específicas, em conhecimentos escolares, são as Práticas de Ensino e similares. Nessa disciplina, o professor formador,

\footnotetext{
${ }^{2}$ Saviani (2006) explícita que o "esquema 3+1" foi adotado nas organizações dos cursos de Licenciaturas e Pedagogia (três anos para o estudo das disciplinas específicas e um ano para a formação didática) foi estabelecido em todo o país por meio do Decreto-Lei n. 1.190, de 04 de abril de 1939.

${ }^{3}$ Para Fiorentini et al. (1998), a "racionalidade técnica" pressupõe que o professor deve ter primeiro uma formação teórica-técnica para, posteriormente, fazer da prática uma instância de aplicação da teoria ou das prescrições técnicas.
} 
normalmente, apresenta formação na disciplina específica em questão e pós-graduação na área de educação, sendo tal aspecto o que tenta fazer a ligação entre os dois eixos da formação, que permaneceram caminhando em paralelo durante toda a licenciatura.

No que tange à Licenciatura em Química, cabe registrar o seu desprestígio, quando comparada com dois outros cursos de graduação da UFMT, nos dias atuais: Bacharelado em Química com Atribuições Tecnológicas e Engenharia Química. Chassot (2014) expressa que, por muito tempo, a licenciatura era apresentada como alternativa para estudantes, que não conseguiam fazer disciplinas avançadas de Química Inorgânica, de Química Orgânica ou de Físico-Química, "para os quais se oferecia, como prêmio de consolação, a possibilidade de fazer umas Didáticas" [grifo do autor] (p. 60). Defende-se com o autor supracitado, que o licenciado, mesmo que não vá operar com aparelhagem tão sofisticada quanto engenheiro químico, nem trabalhar com produtos químicos tão puros quanto o Bacharel em Química, merece uma maior preparação e com excelência, pois vai mexer na cabeça dos jovens e adultos, ensinando-lhes uma nova maneira de ler o mundo com a linguagem química.

Na estrutura curricular de 1997/1, do curso de Química da UFMT ${ }^{4}$, as disciplinas de Prática de Ensino de Química (PEQ) se constituíram como componentes curriculares principais na construção da identidade do educador químico, sendo exclusivas da área de ensino de Química, também responsável pelo Estágio Supervisionado. Essas disciplinas, além do estágio, são responsáveis por desenvolver, de maneira geral, atividades relacionadas com estudos e práticas sobre: a reforma do Ensino Médio, segundo a LDB e as Diretrizes Curriculares para o Ensino Médio; a reforma do Ensino Superior - apresentação e discussão da proposta da reforma de ensino do Curso de Licenciatura em Química - habilidades esperadas do (a) professor (a) de Química; elaboração e planejamento de curso; planejamento de aulas e minicursos; Prática de Ensino e Estágio Supervisionado; regência (UFMT, 1997).

Com a finalidade de superar a racionalidade técnica da estrutura $3+1$ da formação dos licenciandos em Química, dessa estrutura curricular de 1997/1, o grupo de docentes do Laboratório de Pesquisa em Ensino de Química (LabPEQ) criou, no ano de 2003, o projeto de extensão com a realização da Semana de Minicursos das Práticas de Ensino de Química

\footnotetext{
${ }^{4}$ No Departamento de Química do Instituto de Ciências Exatas e da Terra (ICET) da UFMT existem sete áreas para atender os cursos que demandam as disciplinas de Química, em seus currículos, e os cursos de Licenciatura em Química e Bacharelado em Química, sendo estas: Área de Química Analítica, Inorgânica, Orgânica, FísicoQuímica, Bioquímica, Tecnológica e Ensino de Química. A área de Ensino de Química é responsável pelas disciplinas pedagógicas que trabalham com os conhecimentos químicos e, atualmente, é composta por cinco professores.
} 
(SEMIPEQ), que se encontra na XXXIV edição. Esse evento tem por objetivo trazer os estudantes do Ensino Médio, de escolas públicas e privadas, para o ambiente acadêmico da UFMT, favorecendo, assim, maior interação entre universidade e escola. Nesses eventos, os estudantes do Ensino Médio participam de minicursos ministrados pelos estudantes das Práticas de Ensino. Ressalta-se que a partir do ano de 2009, com a implantação do Programa Institucional de Bolsa de Iniciação à Docência (PIBID) Química, no curso de Licenciatura em Química da UFMT, os bolsistas do PIBID, além das atividades inerentes ao programa, também ministravam minicursos na SEMIPEQ.

Na realização dos minicursos da SEMIPEQ, os temas abordados são variados e os licenciandos, estudantes das Práticas de Ensino e/ou bolsistas PIBID em Química, procuram títulos para os minicursos de modo a atrair os estudantes do Ensino Médio, como por exemplo: Conhecendo homeopatia, Estudando os plásticos; Biodiesel; Drogas lúdicas e viciantes; Água: o que você sabe além da fórmula; A Química dos produtos de beleza; Os saberes populares e a Química; Fabricação de produtos de limpeza, A Química do Vagalume, A Química do Chocolate, entre outros.

A avaliação dessa experiência da SEMIPEQ revelou importantes contribuições para todos os envolvidos no processo. Contudo, é importante enfatizar a contribuição desse formato de supervisão para a articulação entre teoria e prática, a partir da experiência da construção e de aplicação dos minicursos. Inicialmente, os estudantes das Práticas de Ensino e bolsistas PIBID apresentavam grandes dificuldades em articular os conhecimentos teóricos, desenvolvidos nas diferentes disciplinas do curso, com as experiências vividas durante a elaboração e a execução desse tipo de extensão. As orientações periódicas, por parte dos docentes da área de ensino de Química, são fundamentais para ajudá-los a superarem tal fragmentação. Por isso, durante o processo da SEMIPEQ, os docentes da área de ensino de Química esclareciam as dúvidas, debatiam as questões e pontos de vistas divergentes, chamando à luz o acúmulo teórico, que o curso lhes proporcionava. Ao mesmo tempo, os estudantes das Práticas de Ensino e bolsistas PIBID, nesse contexto, sentiam-se mais à vontade para expressarem suas ideias e, também, liberdade para a construção de materiais didáticos alternativos em temáticas, que mais lhes agradavam no conhecimento químico.

A experiência narrada da SEMIPEQ tem proporcionado aos discentes, licenciandos e bolsistas do subprojeto Química-PIBID, condições para reorganizar, integrar e aplicar os conhecimentos adquiridos por meio da elaboração de material didático próprio e, muitas vezes, inédito, da análise dos problemas e das dificuldades especiais do ensino de Química, da inserção 
na comunidade, por meio da regência de classe, realizadas em condições materiais e físicas nem sempre necessárias e adequadas. No decorrer dessa atividade, o crescimento intelectual é mútuo: os estudantes de licenciatura colocam em prática os métodos e as técnicas de ensino abordados, em sala de aula, com a supervisão do professor-orientador da disciplina, sendo essa uma forma de introduzir o futuro docente, de maneira confiante, ao meio educacional.

Após esse breve histórico da implantação da formação do educador químico na UFMT do campus Cuiabá, em que se descreveu a estrutura curricular do curso de Licenciatura em Química, vigente de 1997/1 a 2009/2, apresenta-se a partir de agora a atual configuração do curso de Licenciatura em Química, com sua nova estrutura curricular, que entrou em vigência em 2010/1 e que obteve, no ano letivo de 2014 e 2017, o conceito de excelência com a nota cinco $(5,0)$ no indicador de qualidade, que avalia os cursos superiores via o Conceito Preliminar de Curso (CPC) proposto pelo INEP.

Consta no histórico do PPC da Licenciatura em Química, de 2009, que desde a aprovação da nova LDB, $n^{\circ}$. 9394/96, a Educação Brasileira vivenciou um enorme movimento de reflexão dirigido, especialmente, ao estabelecimento de novas diretrizes curriculares em seus diversos níveis. Contudo, muito antes da implementação dessas diretrizes, o curso de Química da Universidade Federal de Mato Grosso iniciou, precisamente em 1994, um processo de avaliação do seu curso de formação de professores de Química para Educação Básica, que culminou no trabalho intitulado: Avaliação Emancipatória do Curso de Licenciatura em Química da UFMT, publicado em 2006 (SANTOS, 1996).

Essa avaliação emancipatória do curso, realizada por Santos (1996), evidenciou a necessidade de reestruturação curricular baseada em vários aspectos, tais como: identidade do curso de Licenciatura em Química como um curso que prepara o discente para o exercício do magistério; simultaneidade da formação profissional docente; redução da carga horária total do curso; mudança do regime acadêmico do curso; funcionamento do curso em um único turno; oferecimento da disciplina Fundamentos Matemáticos, na primeira série, anterior à disciplina de Física, oferecida na segunda série; oferecimento da disciplina; Projeto de Ensino de Química, que deveria acontecer ao longo de todo o curso com apresentação final de monografia; oferecimento de disciplinas de Prática de Ensino de Química e Estágio Supervisionado, em um total de 360 horas; oferecimento da disciplina Evolução dos Conceitos e o resgate da história da construção dos conceitos científicos ao longo das disciplinas (UFMT, 2009).

\footnotetext{
${ }^{5}$ SANTOS, Lydia Maria Parente Lemos dos. Avaliação Emancipatória do Curso de Licenciatura Plena em Química da UFMT. Dissertação de Mestrado em Educação Pública. Cuiabá: UFMT, 1996.
} 
Mediante essa avaliação emancipatória foi constituída uma comissão de reestruturação curricular, composta por representantes de diferentes áreas da Química e por três professoras da área de Ensino de Química, na época, composta pela professora aposentada emérita do Departamento de Química Ms. Lydia Maria Parente Lemos dos Santos e as professoras Dra. Irene Cristina de Mello e a Dra. Elane Chaveiro Soares. As discussões se iniciaram a partir da seguinte questão: qual o perfil profissional que se deseja formar? Esse debate ocorreu no interior das áreas (Físico-Química, Analítica, Orgânica, Inorgânica, Bioquímica e Ensino de Química) e, posteriormente, entre essas.

Nesse mesmo período, em maio de 1998, o MEC solicitou à UFMT sugestões para a elaboração das Diretrizes Curriculares dos cursos de Licenciatura em Química. A comissão, então constituída pelo Colegiado do Departamento de Química da UFMT, elaborou um documento que foi enviado ao MEC, em dezembro de 1998, e que recebeu o seguinte título:

\section{Pressupostos para a definição das Diretrizes Curriculares do Curso de Licenciatura em}

Química. Esse documento apresentava algumas sugestões para as diretrizes curriculares baseadas, essencialmente, no processo de avaliação realizado por Santos (1996).

No ano de 1999, durante o XXXIX Congresso Brasileiro de Química (CBQ), em Goiânia, como reconhecimento do documento elaborado, o curso de Licenciatura em Química da UFMT foi citado pelo representante do MEC, participante do evento, como o melhor curso de Licenciatura em Química do Brasil. Na sequência, a comissão reorganizou o currículo do curso de forma a inserir as disciplinas de Práticas de Ensino de Química, I, II e III, com carga horária total de 300 horas para estrutura curricular antiga do curso de 1997/1 a 2009/2, como já citado anteriormente (UFMT, 2009).

Com a instituição, pelo Conselho Nacional de Educação (CNE), das Diretrizes Curriculares Nacionais (DCNs) para a Formação de Professores da Educação Básica, em nível superior, curso de licenciatura, de graduação plena, mediante Resolução CNE/CP1, de 18 de fevereiro de 2002, a comissão de reestruturação interrompeu o trabalho, que estava em curso, e decidiu participar de um processo de entendimento e debate local e nacional dessas Diretrizes.

O PPC da Licenciatura em Química de 2009 revela que depois de um longo silêncio e pouco consenso sobre as Práticas como Componente Curricular (PCC), bem como um desencontro de opiniões sobre as 400 horas de Estágio Supervisionado, o curso retoma as discussões em 2005, com a constituição de um novo grupo, mas com a manutenção de alguns membros da comissão anterior. Essa comissão organizou, imediatamente, um Seminário de três dias, intitulado: Reestruturação Curricular do Curso de Licenciatura em Química da 
UFMT, para que os docentes, os discentes e os técnicos pudessem discutir os novos rumos do curso, na perspectiva dessas novas diretrizes.

Contudo, o rompimento com as estruturas curriculares anteriores, por parte da comunidade acadêmica, apresentou-se como um dos prováveis aspectos para o não avanço dos trabalhos da comissão e, à medida que a discussão sobre a atuação na formação dos professores para Educação Básica não encontrou ressonância, mas, sobretudo, resistências, inclusive, entre membros da própria comissão. A negação da carga horária de práticas como componentes curriculares e do estágio supervisionado provocou discussões, ao longo de alguns anos, dentro do Departamento de Química da UFMT (UFMT, 2009).

No que tange ao quantitativo de carga horária destinada às práticas como componentes curriculares e estágio supervisionado, Maldaner e Zanon (2010) complementam que há espaços e tempos adequados para desenvolver a Educação Química na organização curricular das licenciaturas atuais. Os autores corroboram que:

\begin{abstract}
Para isso, competências e habilidades básicas de pesquisa educacional precisam ser desenvolvidas. Se isso acontecer, as atuais 400 horas de Práticas de Ensino e 400 de Estágio Supervisionado passam adquirir novos significados na formação de professores. Há quem considere exagerado esse número de horas na atual estrutura curricular das Licenciaturas. De fato, se não soubermos o que fazer na boa distribuição dessas horas, elas parecem muitas. [...] Se não tivermos convicção sobre a importância dessas horas, distribuídas ao longo do curso pelos contatos variados com os conhecimentos próprios de professor, corremos o risco do retorno à antiga fórmula $3+1$ na organização das Licenciaturas (p. 359).
\end{abstract}

Diante desse contexto, e em um processo lento de reestruturação curricular, mas considerado pela comissão de reestruturação necessária para o amadurecimento da forma de entendimento da formação do licenciado em Química, o curso de Licenciatura em Química do campus de Cuiabá foi, de 2005 até 2008, se reorganizando e teve o currículo discutido, em uma constante troca dos membros da comissão de reestruturação.

Em janeiro de 2009, o curso de Licenciatura em Química do Campus Cuiabá recebeu diligência do MEC, instaurada no processo de "Renovação de Reconhecimento". Nessa diligência, o Ministério da Educação, mediante a sua Secretaria de Educação Superior (SESu) e Diretoria de Supervisão (DESUP), solicitou a adequação da estrutura curricular, atividades do curso, perfil do egresso e estágio curricular, em conformidade com as Diretrizes Curriculares Nacionais. Essas solicitações foram atendidas e encaminhadas à Pró-Reitoria de Ensino de Graduação (PROEG), que procedeu aos encaminhamentos necessários (UFMT, 2009). 
Somente em sequência à resposta da diligência, que a comissão de reestruturação do curso finalizou os trabalhos de reestruturação, sendo os documentos que balizaram o PPC da Licenciatura em Química do campus Cuiabá de 2009 os seguintes:

1-Resolução CNE/CP 1, de 18 de fevereiro de 2002, que institui as diretrizes curriculares nacionais para a formação de professores da educação básica, em nível superior, curso de licenciatura, de graduação plena; 2-Resolução CNE/CP 2, de 19 de fevereiro de 2002, que institui a duração e a carga horária dos cursos de licenciatura, de graduação plena, de formação de professores da educação básica em nível superior; 3-Resolução CNE/CES 8, de 11 de março de 2002, que estabelece as diretrizes curriculares para os cursos de bacharelado e licenciatura em Química; 4-Resolução 001/2003/CONAC/UFSJ, de 15 de janeiro de 2003, que determina a obrigatoriedade do projeto pedagógico por curso e fixa diretrizes para elaboração de tal projeto; 5 Legislação vigente sobre formação do profissional da Química (Conselho Federal e Conselho Regional de Química), em especial a resolução normativa no. 60 de 05 de fevereiro de 1982; 6-As normatizações dos conselhos superiores da UFMT; 7- Lei no. 10.436 de 24 de abril de 2002, que dispõe sobre a Língua Brasileira de Sinais - Libras; 8- Lei no. 10.861, de 14 de abril de 2004, que institui o Sistema Nacional de Avaliação da Educação Superior - SINAES; 9- Portaria Normativa no. 40, de 12 de dezembro de 2007, que institui o e-MEC, sistema eletrônico de fluxo de trabalho e gerenciamento de informações relativas aos processos de regulação da educação superior no sistema federal de educação; 10-Lei no. 11.788/2008, de 25 de setembro de 2008, que dispõe sobre o estágio (UFMT, 2009).

A atual estrutura curricular do curso de Licenciatura em Química do Campus Cuiabá entrou em vigência no semestre de 2010/1, com uma carga horária total de 3.620 horas, distribuídas conforme Quadro 1.

Quadro 1 - Distribuição da Carga Horária do Curso de Licenciatura em Química 2010/1

\begin{tabular}{c|c}
\hline Distribuição & Carga Horária \\
\hline Disciplinas Obrigatórias & 2460 horas \\
\hline Disciplinas Optativas Obrigatórias & 120 horas \\
\hline Práticas Pedagógicas como Componente Curricular & 420 horas \\
\hline Estágio Curricular Obrigatório & 420 horas \\
\hline Atividades Complementares & 200 horas \\
\hline Total & 3620 horas \\
\hline
\end{tabular}

Fonte: UFMT (2009)

O PPC de Licenciatura em Química, campus Cuiabá (aprovado pela Resolução CONSEPE n ${ }^{\circ} 183$ de 30 de novembro de 2009, e pela Portaria de Reconhecimento do MEC $n^{\circ}$ 615 de 30 de outubro de 2014) apresenta proposta curricular procurando romper o modelo $3+1$ de formação, revelando um esquema em que a prática é entendida como eixo dessa preparação. Neste sentido, o contato com a prática docente, no PPC, aparece desde os primeiros momentos do curso de formação e tem o entendimento de que, no novo currículo da Licenciatura em Química, é importante que todas as disciplinas tenham vínculo com a educação, de modo que, ao mesmo tempo em que contribuem para a formação relativa ao conhecimento químico, terão 
como foco em como esse conhecimento químico entra, interage e funciona na Escola Fundamental e Média e em situações de educação não escolar.

Nesse sentido, o exercício da Mediação Didática não deve ficar só a cargo dos professores da área de ensino, mas sim de todos os professores das outras áreas, que trabalham no curso de formação de professor licenciatura. A prática como componente curricular - PCC, em cada uma das disciplinas que abrigará, será uma reflexão sobre o conteúdo químico, que está sendo aprendido pelo graduando e que será ensinado por esse, quando de sua atuação profissional como professor. A PCC deve, pois, articular o conhecimento químico ensinado na universidade com condicionantes, particularidades e objetivos desse conhecimento na Educação Básica formal e em outros espaços não escolares de educação.

Segue o Quadro 2, para uma melhor visualização de como a carga horária da PCC foi distribuída, no currículo do curso de Licenciatura em Química.

Quadro 2 - Distribuição da Carga Horária do PCC do Curso de Licenciatura em Química 2010/1

\begin{tabular}{c|c|c}
\hline Semestre & DISCIPLINA & CARGA HORÁRIA - PCC \\
\hline Primeiro & Química Geral I & 30 horas \\
\hline Segundo & Instrumentação para o Ensino de Química I & 60 horas \\
\hline \multirow{2}{*}{ Terceiro } & Instrumentação para o Ensino de Química II & 60 horas \\
\cline { 2 - 3 } & Química Inorgânica I & 30 horas \\
\cline { 2 - 3 } & Química Orgânica I & 30 horas \\
\cline { 2 - 3 } Quarto & Projeto de Ensino de Química & 60 horas \\
\hline \multirow{2}{*}{ Sexto } & Química Analítica Qualitativa & 30 horas \\
\hline \multirow{2}{*}{ Sétimo } & Bioquímica I & 30 horas \\
\cline { 2 - 3 } & Tecnologias Educacionais para o Ensino de & 30 horas \\
& Cuímica & 30 horas \\
\cline { 2 - 3 } & Carga Horária Total De Pcc & 420 horas \\
\cline { 2 - 3 }
\end{tabular}

Fonte: UFMT (2009)

Pode-se observar que o curso de Licenciatura em Química da UFMT campus Cuiabá, com a sua atual estrutura curricular, teve a finalidade básica de formar profissionais reflexivos e aptos a integrar o processo da Educação Básica, de maneira responsável, com participação ativa no desenvolvimento de processos pedagógicos, principalmente, aqueles relacionados com o conhecimento químico (UFMT, 2009).

Por fim, entre os anos de 2016 a 2019, o curso de Licenciatura em Química passou em um processo de novas discussões para o que foi denominado de Adequações Curriculares, que prevê adequação na estrutura curricular do curso para atender as novas $\mathrm{DCN}^{6}$ para a formação

\footnotetext{
${ }^{6}$ Resolução CNE/CP n ${ }^{\circ}$ 2/2015. O artigo 22 da referida Resolução expressa que "os cursos de formação de professores que se encontram em funcionamento deverão se adaptar a esta Resolução no prazo de dois anos, a
} 
inicial em nível superior (cursos de licenciatura, cursos de formação pedagógica para graduados e cursos de segunda licenciatura), que foi promulgada em julho de 2015, a adequação curricular se encontra em processo de análise e de revisão na Pró-Reitoria de Graduação (PROEG) da UFMT, com previsão de implementação no semestre de 2019/2.

Nesta adequação, o curso de Licenciatura em Química da UFMT, campus Cuiabá, será integral (vespertino e noturno), e para o acadêmico se graduar deverá perfazer uma carga horária total de 3.352 horas, distribuídas da seguinte maneira:

Quadro 3 - Distribuição da Carga Horária do Curso de Licenciatura em Química (Adequação Curricular 2019/2)

\begin{tabular}{c|c}
\hline Distribuição & Carga Horária \\
\hline Disciplinas Obrigatórias & 2288 horas \\
\hline Disciplina Optativa Obrigatória & 64 horas \\
\hline Prática como Componente Curricular & 400 horas \\
\hline Estágio Curricular Obrigatório & 400 horas \\
\hline Atividades Teórico-Práticas & 200 horas \\
\hline Total & 3352 horas \\
\hline
\end{tabular}

Fonte: Elaboração do autor (2019)

Após esse breve histórico do contexto do curso de Licenciatura em Química, dá-se a conhecer a inserção do PIBID, no contexto da UFMT e, mais especificamente, no curso de Licenciatura em Química do campus Cuiabá, com suas atividades iniciadas a partir do ano de 2009.

\section{O Programa InSTITUCIONAL de BolSA DE INICIAÇÃo À DoCÊNCIA NA UFMT}

A Universidade Federal de Mato Grosso participa do PIBID desde o lançamento do primeiro edital ${ }^{7}$, cujo programa institucional está ancorado na Coordenação de Programas de Formação Docente da Pró-Reitoria de Ensino de Graduação (PROEG). Para o desenvolvimento do Programa nos cursos de licenciatura, a UFMT propicia a contrapartida da instituição em espaços físicos, em materiais permanentes e em outros recursos, que não são financiáveis pela Coordenação de Aperfeiçoamento de Pessoal de Nível Superior (CAPES) ${ }^{8}$.

contar da data de sua publicação". Essa Resolução considera que deve constar a articulação entre a graduação e a pós-graduação e entre pesquisa e extensão como princípio pedagógico essencial ao exercício e ao aprimoramento do profissional do magistério e da sua prática educativa.

${ }^{7}$ Edital no 01/2007 - Diretoria de Educação Básica Presencial (DEB)/CAPES.

${ }^{8}$ A CAPES foi criada por Anísio Teixeira em 11 de julho de 1951, pelo Decreto $\mathrm{n}^{\circ} 29.741$ com a finalidade de garantir a existência de pessoal qualificado em quantidade suficiente para suprir as necessidades e as demandas dos empreendimentos públicos e privados, visando o desenvolvimento do Brasil e se concentrou durante décadas, na Educação Superior, em especial a pós-graduação stricto-sensu, desempenhando papel fundamental na expansão e na consolidação dos programas de pós-graduação em todos os Estados da federação. 
No Estado de Mato Grosso existe um grande déficit de professores habilitados para atuar na Educação Básica e a UFMT é a IES responsável por parte considerável da formação inicial de professores para trabalharem nas áreas de Códigos e Linguagens, Pedagogia, Ciências Sociais, Matemática e Ciências Naturais ${ }^{9}$. A dificuldade na formação inicial dos professores se soma aos aspectos regionais do Estado por esse possuir grandes extensões territoriais, o que lhe confere, em âmbito educacional, maiores desafios em todos os aspectos, sobretudo, na formação inicial. Associam-se a esses aspectos, outros que contribuem para tornar o ensino mais deficitário, tais como: baixa remuneração do corpo docente; insuficiência na formação continuada dos professores; condições escolares desfavoráveis; problemas de gestão escolar, entre outros. Esse quadro, de acordo com Mello (2012), tem desencadeado muitos males, tais como: violência, desvalorização da escola e do professor perante os educandos e suas famílias, evasão escolar e, sobretudo, baixo nível de aprendizagem. Diante desse panorama, inerente à formação inicial no Estado de Mato Grosso, o incentivo à docência por parte do PIBID, ao menos em sua formação inicial, nas áreas supracitadas, torna-se altamente relevante.

O PIBID da UFMT envolve os campi de Cuiabá, de Barra do Garças, de Rondonópolis e de Sinop em todas as licenciaturas presenciais e a licenciatura em Pedagogia a distância. O projeto institucional do PIBID/UFMT está alicerçado por alguns eixos norteadores, que formam uma espécie de engrenagem, que orienta e articula as atividades dos subprojetos, sendo estes: Programa de Desenvolvimento Institucional (PDI), Diretrizes Curriculares Nacionais para o Ensino Médio (DCNEM), Avaliação Emancipátória, Interdisciplinaridade, Seminários Integradores e a pesquisa como princípio formativo. Observando os eixos norteadores do projeto institucional do PIBID/UFMT se nota que está em consonância com a concepção de formação que Nóvoa propõe: “A formação passa pela experimentação, pela inovação, pelo ensaio de novos modos de trabalho pedagógico, a formação passa por processos de investigação, diretamente articulados com a prática"(1992, p. 28). A Figura 1 esboça o desenho metodológico do Programa:

\footnotetext{
${ }^{9}$ Os cursos de Licenciatura em Química e Física são ofertados somente por IES da rede federal de ensino, UFMT e IFMT.
} 
Figura 1 - Desenho estratégico/interacionista do Programa PIBID

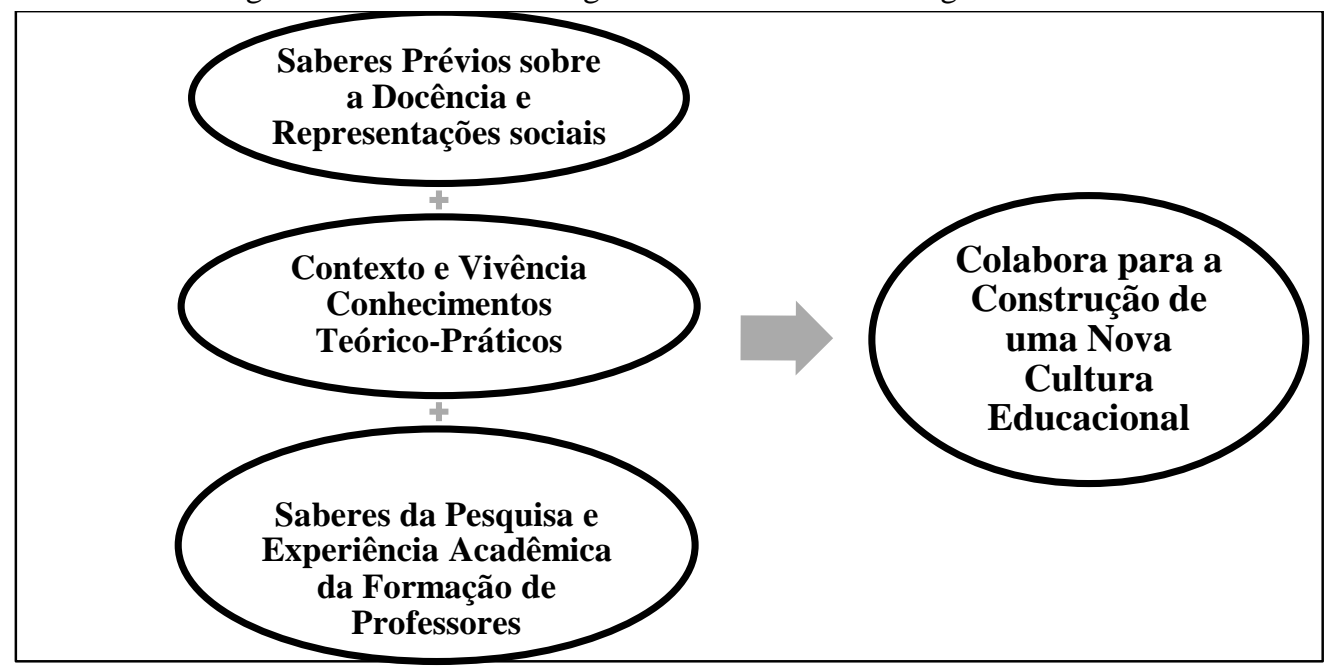

Fonte: Elaboração do autor, baseado em DEB/CAPES (2013a)

A reconstrução de uma nova cultura educacional, que o PIBID pretende alcançar, está pautada em pressupostos teórico-metodológicos que articulam teoria-prática, universidadeescola e formadores-formandos. Nesse sentido, e pautado no terceiro princípio pedagógico do PIBID, que trata de criar inovações na educação, defende-se com Imbernón (2011), que o professor não deve ser um técnico para desenvolver ou implementar inovações prescritas, mas deve se converter em um profissional que participe, de forma crítica e ativamente, no verdadeiro processo de inovação e de mudança, sempre partindo do seu próprio contexto em um processo dinâmico e flexível. O autor defende que se deve considerar o profissional da educação:

Como um agente dinâmico cultural, social e curricular, que deve ter a permissão de tomar decisões educativas, éticas e morais, desenvolver o currículo em um contexto determinado e elaborar projetos e materiais curriculares em colaboração com os colegas, situando o processo em um contexto específico controlado pelo o próprio coletivo (IMBERNÓN, 2011, p. 24).

Os subprojetos das licenciaturas específicas da UFMT devem apresentar como ponto de partida a dimensão interdisciplinar e transdisciplinar, instituindo os necessários coletivos organizados, como propostos nos PCNEM, PCN+, OCNEM e Orientações Curriculares do Estado de Mato Grosso. Essa orientação à constituição das propostas dos subprojetos a serem desenvolvidos está subsidiado pela experiência inovadora do curso de Licenciatura em Ciências Naturais e Matemática da UFMT, que é a de promover, por meio de um trabalho interdisciplinar e transdisciplinar, ações curriculares que proporcionem o diálogo entre professores das disciplinas das áreas envolvidas no PIBID, na perspectiva de construirem propostas pedagógicas, que busquem a contextualização interdisciplinar, social e cultural. Nessa perspectiva, o objetivo dos subprojetos, em cada área específica, é de incrementar experiências 
inovadoras, com o objetivo de consolidar práticas diferenciadas na formação dos licenciandos (NÓVOA, 1992).

O projeto institucional PIBID/UFMT estabelece relações com a identidade da política institucional e se encontra orientado por alguns objetivos como: ampliar a oferta e melhorar a qualidade do ensino de graduação e de pós-graduação; fortalecer o processo de inclusão social; ampliar a articulação com a sociedade e contribuir para a ambiência universitária. Em decisão coletiva se institui, no PIBID/UFMT, um conselho deliberativo, composto por representantes dos membros participantes, com o objetivo de deliberar sobre as mais variadas questões, sobretudo, as relacionadas à aplicabilidade dos recursos disponíveis, tendo o mesmo intuito a figura do pibidiano voluntário, que embora não receba bolsa, possui atribuições claramente definidas nos subprojetos e participam, também, como colaboradores eventuais ou voluntários, os professores das escolas da Educação Básica e docentes da UFMT (MELLO, 2012).

De acordo com Mello (2012), as ações do PIBID na UFMT são variadas como:

\begin{abstract}
Definição da política de execução do PIBID/UFMT com os coordenadores dos subprojetos; seleção dos bolsistas e professores supervisores; constituição de grupos de apoio, nas escolas e na universidade; socialização do projeto institucional nas escolas envolvidas; organização e execução dos Seminários Integradores, de forma a realizar integração entre os participantes, com a pós-graduação e com os supervisores de estágio supervisionado das licenciaturas envolvidas, na UFMT; levantamento de pesquisas e diagnósticos educacionais relativas às áreas específicas em Mato Grosso; realização do diagnóstico educacional nas escolas; organização e execução dos Ciclos de debates (envolvendo, inclusive, a pós-graduação) e definição das ações coletivas; publicação das atividades do PIBID/UFMT no Portal do Professor do MEC, dentre outros (p. 17-18).
\end{abstract}

Nessa perspectiva, Nóvoa (1992, p. 26) contribui dizendo que: "a troca de experiências e a partilha de saberes consolidam espaços de formação mútua, nos quais cada professor é chamado a desempenhar, simultaneamente, o papel de formador e de formando".

Nas atividades dos seminários integradores do PIBID foram expressas também algumas dificuldades na execução e no desenvolvimento dos subprojetos, tais como: articulação dos horários dos bolsistas, supervisores e coordenadores de área, haja vista que alguns cursos de licenciatura ocorrem em período integral, atrasos eventuais nos pagamentos das bolsas e na liberação da verba de custeio para o desenvolvimento dos subprojetos, a alta rotatividade dos bolsistas, as dificuldades dos coordenadores de área em articularem projetos e atividades inter e transdisciplinares, entre outros.

Diante dos apontamentos significativos, já vivenciados pelo programa, reconhece-se esse como uma iniciativa, por parte do Governo Federal, em valorização no ingresso e 
permanência na docência aos estudantes de licenciatura, pois se sabe que essa valorização perpassa outros fatores.

Na pesquisa empreendida por Gatti (2013) sobre Valorização da docência e avaliação do trabalho docente, a pesquisadora revela que a atividade docente, de modo mais abrangente, é representada como carregada socialmente por sinalizações contraditórias e que têm se mantido ao longo de décadas. Por exemplo, pesquisas empíricas recentes mostram como os jovens têm uma representação contraditória em relação à figura dos professores. Essa representação é composta, de um lado, por uma imagem positiva do papel do professor para a sociedade e para sua própria educação, e de outro, a imagem de seu baixo reconhecimento como profissional, em função de sua carreira ser pouco promissora, em termos financeiros, e pelas dificuldades visualizadas em seu exercício profissional, dadas as condições inóspitas de trabalho que lhes são oferecidas e o comportamento e as motivações das crianças e dos jovens na atualidade.

A valorização social dos professores, nesse sentido, passa por uma reconstrução sociocultural dessas representações, em forma menos ambígua ou contraditória, e esse movimento depende de condições concretas relacionadas ao contexto de formação e de trabalho dos docentes na Educação Básica. A mudança em representações sociais é um processo sóciohistórico-cultural complexo e lento, especialmente, quando uma representação perdura por longo tempo sem ser abalada por fatos de impacto efetivo e duradouro. Gatti explicita que:

\begin{abstract}
A representação de não valorização da docência na Educação Básica vem perdurando uma vez que a constituição sócio-histórica e política de elementos para a superação e reconstrução dessas representações sociais não tem alcançado efetividade real. A gestão pública da educação tem faltado, em seus vários níveis, um projeto articulado de formação docente e de trabalho nas escolas, com política bem estruturada, organizada e planejada. A educação escolar pública, pela forma que é realizada nas diferentes comunidades, favorece a construção de uma imagem fragmentada de educação, empobrecida pela condição oferecida a seus professores e alunos (2013, p. 155).
\end{abstract}

Nesse sentido, a pesquisadora revela que valorizar o magistério com políticas coerentes e convergentes, com apoio efetivo aos docentes, que estão atuando e aos futuros professores é o mote, e se apresenta como um dos vários caminhos rumo a essa valorização. Sendo assim, o PIBID se revela como uma política de fundamental importância no cenário nacional na trajetória dessa valorização à docência.

Houve a intencionalidade de com esta breve descrição do Programa Institucional de Bolsa de Iniciação à Docência, como parte de uma política nacional de formação de profissionais do magistério da Educação Básica na UFMT, contextualizar um dos contextos formativos dos licenciandos em Química da UFMT. Este esclarecimento se justifica pelo fato 
de não se estar estudando a proposta política, em si, mas por ter convicção de que a proposta não garante que as melhorias pretendidas na formação e no ensino da Educação Básica se efetivarão, pois há muitas interferências nos locais de trabalho dos professores, ou seja, as condições de trabalho docente, via de regra, são adversas na escola pública.

Exatamente por não poder generalizar o contexto formativo do PIBID, em que pese a opinião pessoal do pesquisador, a importância desse programa, no cenário nacional, no âmbito da formação inicial de professores, como uma das políticas de valorização à docência, apresenta-se na próxima seção a constituição e as experiências do subprojeto Química/PIBID na UFMT.

\section{ITINERÁrio do SubProjeto Química - PIBID EM Cuiabá Na UFMT}

O Subprojeto Química/PIBID ${ }^{10}$ foi implantado na UFMT campus Cuiabá, envolvendo discentes e docentes dos cursos de Licenciatura em Química e professores do Ensino Médio da rede pública, desde o lançamento do primeiro edital $n^{\circ} 01$ da DEB/CAPES, de 2007. Na participação do edital 2007, a coordenadora inicial do subprojeto foi a educadora química Dra. Elane Chaveiro Soares, que escreveu o subprojeto da Química para submissão ao edital, tendo sido aprovado pela DEB/CAPES. A professora fez a seleção das escolas participantes, dos professores supervisores e de estudantes, tendo sido esta equipe composta por onze bolsistas estudantes da licenciatura, um voluntário, dois supervisores, um por escola, um coordenador do subprojeto, e pelo grupo de apoio do Laboratório de Pesquisa e Ensino de Química LabPEQ/UFMT.

Esse subprojeto, aprovado pelo edital 2007, apenas teve o início de suas atividades a partir do primeiro semestre do ano de 2009 por problemas logísticos da CAPES. O período de início das atividades do subprojeto coincidiu com o afastamento para qualificação docente, em nível doutoral, da coordenadora que elaborou o subprojeto de Química e quem assumiu a coordenação foi a professora aposentada Ms. Lydia Maria Parente Lemos dos Santos, durante todo o primeiro semestre do ano de 2009. Nesse mesmo ano, ocorreu o ingresso deste pesquisador na UFMT, como educador químico para a área de ensino de Química do curso de Licenciatura em Química do campus Cuiabá.

$\mathrm{Na}$ oportunidade, ao ingressar como docente no curso de licenciatura, trabalhando com as disciplinas de Práticas de Ensino de Química (PEQ) da estrutura curricular de 1997/1, este

\footnotetext{
${ }^{10}$ Os projetos de cada área de conhecimento em específico vinculados ao projeto institucional da UFMT do PIBID são denominados de subprojetos, por isso a denominação do projeto de Química-PIBID ser chamado de subprojeto Química-PIBID.
} 
pesquisador assumiu também a coordenação e a condução do subprojeto Química-PIBID do campus Cuiabá, estando na coordenação desse projeto a partir do segundo semestre de 2009 até o seu término, em dezembro de 2010, e depois nos anos de 2011 a janeiro de 2013, com a participação do subprojeto no novo edital da DEB/CAPES de 2011.

A experiência de conduzir os trabalhos do PIBID se revelou, à época, muito desafiadora para a formação profissional, pois ao mesmo tempo em que se estava constituindo como formador de professores, pois havia acabado de ingressar na carreira do Magistério Superior, estando na situação de programar atividades diferenciadas no subprojeto para a formação desses licenciandos, de forma imediata, para atuarem na Educação Básica. Portanto, considera-se essa experiência de passagem pelo PIBID muito significativa para a constituição deste pesquisador como formador de professores de Química, no contexto real de trabalho, ou em outros termos, no chão da escola. Ao fazer essa breve reflexão sobre a passagem pelo PIBID e apoiando-se em um dos teóricos, que dão subsídios à pesquisa foi possível compreender o que Tardif (2012) chamou de temporalidade do saber, uma vez que o amálgama de saberes para ser constituído e consolidado como profissional da educação é adquirido no contexto de história de vida, e que para formar um professor foi preciso com que este pesquisador aprendesse a formar este professor e isso aconteceu e está acontecendo com o tempo, progressivamente, em relação ao desenvolver do trabalho docente.

O subprojeto Química/PIBID (edital 2007) foi desenvolvido nas Escolas Estaduais com as quais a universidade possuía convênio estabelecido com a Secretaria de Estado de Educação de Mato Grosso (SEDUC/MT), localizadas no município de Cuiabá, fazendo parte a Escola Estadual Dona Maria de Arruda Muller - Liceu Cuiabano, situada na região central da cidade e que recebe estudantes de todos os bairros da capital. Destaca-se, também, o fato da escola possuir um amplo espaço físico e dispor de laboratório de Química. E a outra foi a Escola Estadual André Avelino Ribeiro, situada na periferia de Cuiabá. As duas escolas de Educação Básica, participantes do PIBID, possuíam reconhecidamente problemas de ensino e aprendizagem na área de Ensino de Química, identificados nas atividades de estágio supervisionado das disciplinas de Práticas de Ensino de Química (PEQ) I, II e III do curso de Licenciatura em Química da UFMT e baixa média na avaliação no Exame Nacional de Ensino Médio (ENEM).

Após o término das atividades do subprojeto Química-PIBID, do edital 2007, no ano de 2011 foi lançado um novo edital, como citado anteriormente, do qual o curso de Licenciatura em Química da UFMT do campus Cuiabá participou da seleção e teve a proposta aprovada pela 
DEB/CAPES. As atividades desse projeto foram realizadas somente em uma escola, que já havia participado do PIBID, no edital anterior, que foi a Escola Estadual Dona Maria de Arruda Muller - Liceu Cuiabano, com cinco bolsistas estudantes de licenciatura, um estudante voluntário, uma professora supervisora da escola e este pesquisador como coordenador do subprojeto.

É imperioso destacar que, no primeiro edital (de 2007), havia onze bolsas para os estudantes e no segundo (edital de 2011) havia cinco bolsas, e conforme os estudantes concluíam o curso de graduação, na vigência do subprojeto, eram feitas outras/novas seleções para novos estudantes da Licenciatura em Química para ocupar a bolsa e para participar das atividades do subprojeto nas escolas. Das edições de 2007 e 2011, do subprojeto QuímicaPIBID, tiveram a oportunidade de vivenciar as atividades de iniciação à docência em Química vinte e três estudantes da licenciatura, todos oriundos da estrutura curricular de 1997/1 do curso de Licenciatura em Química da UFMT e como essa estrutura tinha a característica de formação nos moldes do currículo 3+1, a participação no PIBID se revelou de fundamental importância na formação inicial desses licenciados.

O subprojeto Química-PIBID participou novamente do edital de seleção dos subprojetos 2013 da DEB/CAPES que, nessa edição, passou a ser de fluxo contínuo, agora com a coordenação da professora Dra. Elane Chaveiro Soares, e nessa versão atual do subprojeto, esse está sendo desenvolvido em duas escolas de Educação Básica de Cuiabá: a Escola Estadual Dona Maria de Arruda Muller - Liceu Cuiabano, situada na região central da cidade e que participa, pela terceira vez, do subprojeto e a Escola Estadual Pascoal Ramos situada na periferia de Cuiabá. Essa versão do subprojeto conta com quinze bolsistas estudantes da licenciatura, todos da nova estrutura curricular do curso implantado em 2010/1, dois professores supervisores, um por escola, e um coordenador de subprojeto.

O Subprojeto Química-PIBID tem por finalidade o incentivo à docência em Química, pois se entende que a melhora na atuação profissional passa pelo conhecimento e pelo controle das variáveis, que intervém no exercício da profissão. Em função dos processos de ensino e aprendizagem serem extremamente complexos, torna-se necessário que se disponha e se utilizem referenciais que ajudem a interpretar o que acontece nos processos formativos. Tais referenciais puderam ser utilizados no planejamento e no próprio processo formativo (ZABALA, 1998).

Nesse sentido, o subprojeto Química-PIBID desenvolveu e desenvolve seu trabalho junto com os bolsistas estudantes por meio de trabalhos e de ações que estimulam a construção 
de propostas pedagógicas, por meio de ações curriculares, que incentivem a contextualização interdisciplinar, social e cultural como proposto nos Parâmetros Curriculares Nacionais para o Ensino Médio (PCNEM), e Orientações Curriculares Nacionais para o Ensino Médio (OCNEM), pois é mister que a abordagem dos conceitos e dos conteúdos de Química seja coerente com a visão atualizada, em termos científicos e pedagógicos, contemplando avanços tanto do conhecimento químico quanto das concepções da Química como ciência, a historicidade e as implicações sociais desta área, sendo essencial a busca sistemática de novas referências e de novas e diversificadas fontes de informação (BRASIL, 2008).

Diante desse contexto, para incentivar e auxiliar a formação dos futuros professores de Química da Educação Básica, o subprojeto Química-PIBID realizou e realiza atividades, tais como:

- Ciclo de Estudos - Apresentação de seminários com temas relacionados à Educação, Formação de Professores e Ensino de Ciências/Química;

- Realização de Pesquisas na área de ensino de Ciências/Química;

- Participação em eventos (encontros, seminários, congressos entre outros) relacionada ao ensino de Ciências/Química;

- Acompanhamento dos bolsistas nas unidades escolares conveniada com a UFMT para o processo de Estágios tais como: Observação, Monitoria e Regência;

- Participação dos bolsistas na Semana de Minicursos das Práticas de Ensino de Química da UFMT;

- Participação dos bolsistas na semana pedagógica das unidades escolares bem como no planejamento anual da disciplina de Química;

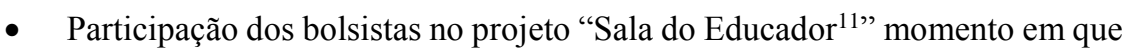
os docentes das unidades escolares passam por "Formação Continuada";

- Participação dos bolsistas da Química em atividades interdisciplinares com outros bolsistas PIBID dos subprojetos de Biologia, Física e Matemática (UFMT, 2010).

Das ações do subprojeto Química-PIBID, com a intenção de acompanhar as OCNEM de Química para o Ensino Médio e realizar a Avaliação Emancipatória das escolas parceiras, o subprojeto orientou e orienta os licenciandos bolsistas que a dinâmica da vida do professor na escola pode e precisa se voltar mais para o favorecimento da (re) organização da prática curricular, da (re) construção do processo ensino e aprendizagem, das decisões do que ensinar, de como ensinar, de como avaliar significativamente o que foi aprendido, da consolidação de espaços efetivamente transformados da dinâmica social, por meio da instrumentalização

\footnotetext{
${ }^{11}$ A Sala do Educador se trata de uma proposta política de formação continuada implementada nas unidades escolares da rede estadual de Mato Grosso, sendo acompanhada pelo Centro de Formação de Professores CEFAPRO da Secretária Estadual de Educação de Mato Grosso - SEDUC/MT.
} 
intelecto-cultural dos cidadãos potencialmente ocupantes de posições decisivas no cenário coletivo da sociedade.

É importante destacar que a definição dos conteúdos de Química a serem trabalhados nas escolas parceiras do subprojeto é um dos temas principais na capacitação dos bolsistas e dos professores supervisores (o que se deve ensinar de Química? Por quê? Como? E para quê?). Esses conteúdos só são definidos após o diagnóstico do contexto escolar, da leitura do Projeto Político Pedagógico (PPP) da escola e do estudo sistemático das Orientações Curriculares Nacionais para o Ensino de Química.

\section{CONSIDERAÇões FinaIS}

Ao fazer esses relatos, registra-se o processo histórico do curso de Licenciatura em Química do Campus Cuiabá da UFMT, e as experiências do subprojeto de Química-PIBID para o incentivo à iniciação à docência em Química. Destaca-se que a atuação dos bolsistas do PIBID, no ambiente real de ensino, vem sendo realizada mediante diagnóstico do contexto escolar, por meio da inserção dos bolsistas e observação do dia a dia escolar do sistema público de ensino. Os bolsistas, durante toda a execução, planejamento de atividades de ensino, elaboração de materiais didáticos, tiveram o apoio dos integrantes do Laboratório de Pesquisa e Ensino de Química (LabPEQ), dos professores supervisores e coordenador do subprojeto. E cabe destacar que outra atividade, de grande relevância, desenvolvida no subprojeto, pelos bolsistas, envolve a realização de atividades experimentais na perspectiva de levar aos estudantes da Educação Básica os conhecimentos químicos contextualizados, com base nos fenômenos diários.

Ao finalizar esse breve contexto do programa PIBID, no curso de Licenciatura em Química da UFMT, não se poderia deixar de evidenciar a crise que esse programa passou junto ao DEB, no âmbito da estrutura organizacional da CAPES, devido à atual conjuntura política financeira do Brasil nos anos de 2015 e 2016.

As perspectivas negativas à época de sua continuidade levantou um clamor pela continuidade do Programa PIBID organizado pelos coordenadores e supervisores dos subprojetos PIBID das IES de todo o Brasil, juntamente com os pibidianos, apoiado justamente nas inúmeras conquistas para uma formação docente mais qualificada. Os bolsistas não são meros expectadores ou executores no Programa, nem tampouco estão no Programa só pela bolsa que recebem. No entanto, de acordo com Soares (2016), é viável perguntar se esta última questão também pode ser feita ao Programa de iniciação cientifica, o PIBIC. A campanha para 
a permanência do PIBID ganhou eco nas redes sociais no final do ano de 2015 e todo o ano de 2016 com a chamada \#FicaPIBID ${ }^{12}$.

Nesta perspectiva, Soares (2016) corrobora que, aqueles que aquecem os bastidores políticos do país precisam compreender que a educação é processual e dinâmica e que a incorporação de transformações é urgente e necessária, mas que isso precisa ser feito de forma gradativa e seriamente assistida. Isso quer dizer que os investimentos na formação docente devem vir acompanhados de políticas de valorização da profissão docente, sem a qual, qualquer programa ou projeto se inviabiliza pela própria evasão.

\section{REFERÊNCIAS}

CHASSOT, Áttico Inácio. Catalisando Transformações na Educação. Ijuí: Ed. UNIJUÍ, 1993.

CHASSOT, Áttico Inácio. Para que(m) é útil o ensino? 3.ed. Ijuí: Ed. Unijuí, 2014.

FIORENTINI, Dario et al. Saberes Docentes: Um Desafio para Acadêmicos e Práticos. In: FIORENTINI, Dario et al. (orgs.). Cartografias do Trabalho Docente. 1. ed. Campinas, SP: Mercado das Letras, 1998, p. 307-335.

GATTI, Bernardete Angelina. Valorização da Docência e Avaliação do Trabalho Docente. In: GATTI, Bernardete Angelina (Org). O Trabalho Docente, Avaliação, Valorização, Controvérsias. Campinas-SP: Autores Associados, São Paulo: Fundação Carlos Chagas, 2013.

IMBERnÓN, Francisco. Formação Docente e Profissional. 9. ed. São Paulo: Cortez, 2011.

MALDANER, Otávio Aloísio. A Pós-Graduação e a Formação do Educador Químico. In: ROSA, Maria Inês Petrucci; ROSSI, Adriana Vitorino. Educação Química no Brasil Memórias, Políticas e Tendências. 1.ed. Campinas, SP: Editora Átomo, 2008, p. 269-288.

MALDANER, Otávio Aloísio; ZANON, Lenir Basso. Pesquisa Educacional e Produção de Conhecimento do Professor de Química. In: SANTOS, Wildson Luiz P. dos; MALDANER, Otávio Aloísio. Ensino de Química em Foco. 1.ed. Ijuí: Ed. Unijuí, 2010, p. 331-365.

MELLO, Irene Cristina. Iniciação à Docência na UFMT. Cuiabá: EdUFMT, 2012.

NÓVOA, Antonio. Formação de Professores e Profissão Docente. In: Os Professores e a Sua Formação. Lisboa: Dom Quixote, 1992, p. 77-92.

\footnotetext{
${ }^{12}$ Cabe destacar, que no ano de 2018 a Capes lançou um novo edital para o Programa PIBID, Edital Capes $n^{\circ}$ 07/2018, com novos moldes de funcionamento para os anos de 2018-2019, sendo que no PIBID participam somente licenciandos do primeiro ao quarto semestre do curso. E lançou o Edital Capes no 06/2019 para o Programa Residência Pedagógica, para funcionamento também nos anos de 2018-2019, e nesse programa participam somente licenciandos do quinto ao oitavo semestre do curso. A Licenciatura em Química do campus Cuiabá participa do PIBID e da Residência Pedagógica desses novos editais.
} 
PÉREZ GÓMEZ, Angel. O Pensamento Prático do Professor: A Formação do Professor como Profissional Reflexivo. In: NÓVOA, Antonio. Os Professores e a Sua Formação. Lisboa: Dom Quixote, 1992, p. 77-92.

RIBEIRO, Marcel Thiago Damasceno. Saberes Científicos e Pedagógicos de Conteúdo expressos pelos professores egressos do Programa de Bolsas de Iniciação à Docência em Química da UFMT. 2016. 161f. Tese (Doutorado em Educação em Ciências e Matemática), REAMEC, Universidade Federal de Mato Grosso. Cuiabá, 2016.

SANTOS, Wildson Luiz Pereira dos. O Ensino de Química para Formar Cidadão: Principais Características e Condições para a sua implantação na escola secundária brasileira. 1992. Dissertação (Mestrado em Educação), Faculdade de Educação, Universidade Estadual de Campinas. Campinas, 1992.

SAVIANI, Dermeval. Pedagogia e Formação de Professores no Brasil: vicissitudes dos dois últimos séculos. In: IV Congresso Brasileiro de História da Educação, UCG, Goiânia, 2006. Disponível em: http://www.sbhe.org.br/novo/congressos/cbhe4/coordenada-eixo01DS.htm. Acesso em: 05/02/2015.

SOARES, Elane Chaveiro. PIBID/QUÍMICA/UFMT e a Ideia de Autoconceito Profissional Docente: Perspectivas e Conquistas. Anais do XVIII ENDIPE. 2016, p. 1-10.

SHÖN, Donald A. Formar Professores como Profissionais Reflexivos. In: NÓVOA, Antonio. Os Professores e a Sua Formação. Lisboa: Dom Quixote, 1992, p. 77-92.

SCHNETZLER, Roseli Pacheco; ARAGÃO, Rosália Maria Ribeiro de. Importância, Sentido e Contribuições de Pesquisas para o Ensino de Química. Revista Química Nova na Escola. n.1, p. 27-31, maio 1995.

SCHNETZLER, Roseli Pacheco. A Pesquisa no Ensino de Química e a Importância da Química Nova na Escola. Química Nova, São Paulo: SBQ, supl. 1, p. 14-24, 2002.

SCHNETZLER, Roseli Pacheco. A Pesquisa no Ensino de Química no Brasil: conquistas e perspectiva. Revista Química Nova na Escola. n.20, p. 49-54, novembro 2004.

SCHNETZLER, Roseli Pacheco. Educação Química no Brasil - 25 anos de ENEQ Encontro Nacional de Ensino de Química. In: ROSA, Maria Inês Petrucci; ROSSI, Adriana Vitorino. Educação Química no Brasil - Memórias, Políticas e Tendências. 1.ed. Campinas, SP: Editora Átomo, 2008, p. 17-38.

SCHNETZLER, Roseli Pacheco. Apontamentos Sobre a História do Ensino de Química. In: SANTOS, Wildson Luiz P. dos; MALDANER, Otávio Aloísio. Ensino de Química em Foco. 1.ed. Ijuí: Ed. Unijuí, 2010, p. 51-75.

UNIVERSIDADE FEDERAL DE MATO GROSSO. Projeto Pedagógico do Curso de Licenciatura Plena em Química. Cuiabá: UFMT/ICET, 1997.

UNIVERSIDADE FEDERAL DE MATO GROSSO. Projeto Institucional do PIBID. Cuiabá: UFMT/PROEG, 2007. 
UNIVERSIDADE FEDERAL DE MATO GROSSO. Resolução CONSEPE $n^{\circ} 183$ de 30 de novembro de 2009. Projeto Pedagógico do Curso de Licenciatura Plena em Química. Cuiabá: UFMT/ICET, 2009.

UNIVERSIDADE FEDERAL DE MATO GROSSO. Relatório Final de Atividades do subprojeto Licenciatura Plena em Química, campus Cuiabá, do Programa Institucional de Bolsas de Iniciação à Docência - PIBID, Edital DEB/CAPES, 2007. Cuiabá: UFMT/PROEG, 2010.

ZABALA, Antoni. A Prática Educativa Como Ensinar. Porto Alegre: ArtMed, 1998.

Recebido em: 12 de abril de 2019.

Aprovado em: 18 de junho de 2019. 